\title{
Conceptual prevalence in palliative care amongst the physicians of Bangabandhu Sheikh Mujib Medical University: a comparison between the post-graduate trainees and the trainers
}

\author{
Nezam Uddin Ahmad ${ }^{1}$, Farzana Khan ${ }^{2}$, Sayeda Sharmin Quadir ${ }^{2}$, Mizanur Rahman ${ }^{3}$, \\ Manzoorul Hoq Laskar ${ }^{3}$, Akhtaruzzaman AKM ${ }^{1}$
}

\begin{abstract}
${ }^{1}$ Associate Professor, Department of Anaesthesia, Intensive Care and Pain Medicine, BSMMU, Dhaka, ${ }^{2}$ Medical Officer, Department of Anaesthesia, Intensive Care and Pain Medicine, BSMMU, Dhaka, ${ }^{3}$ Consultant, Department of Anaesthesia, Intensive Care and Pain Medicine, BSMMU, Dhaka

* Corresponding author: Associate Professor, Department of Anaesthesia, Intensive Care and Pain Medicine, BSMMU, Dhaka, Bangladesh
\end{abstract}

\begin{abstract}
:
Background: Palliative care program has no place either in the national health care service or in undergraduate or post graduate medical curriculum in Bangladesh.

Introduction: First Palliative Care Service began in the only medical university of the country in 2007 and still in its early infancy. We hypothesized that medical practitioners mostly have low level of understanding in palliative care
\end{abstract}

Aim of the study: To assess the level of self-perception and understanding in palliative care amongst the post graduate trainees and their trainers in the university and to find out if there is any difference between the two groups.

Materials and methods: 127 post graduate trainees and 81 post graduate teachers participated in a survey study during the first one year of the beginning of the service in the university. The data were collected after the survey and the responses were analyzed.

Results: The reported level of perception in palliative care appeared to be present in both the groups even without any formal teaching or training. The trainees claimed to have more exposure and understanding than the post graduate teachers who happen to be their trainers. Actual level of understanding was difficult to assess.

Conclusion: The result of this survey make a strong case of further evaluating the actual level of understanding and skill determination required in the field of palliative care in different institutions. This will enable to compare and to determine the sharp contrast for palliative care need versus lack of education and training in this field.

Key words: palliative care; concepts; doctors; medical education; Bangladesh

(Journal of BSA, 2009; 22(1): 26-31)

\section{Introduction:}

Palliative care is all about looking after people with illnesses that can not be cured, relieving their sufferings and supporting them through difficult time. It is a fast growing field in the developed part of the world as contemporary medicine has begun to reemphasize the importance of palliative and endof- life care ${ }^{1}$.

Aranda rightly said in 1999 that 'Bangladesh has one cancer unit for a population of 120 million people, and although most patients are diagnosed with advanced cancer, there is no plan for palliative care program $^{2}$.

This remark remains more or less same till date except for a few more cancer units in the country. Appropriate symptom control and palliative care for incurably ill patients is not explicitly acknowledged as an important issue neither in public nor in private health care facilities. Medical education and health care service is more cure oriented and Quality of 
Life (QOL) issues are rarely considered. There is a huge unmet hidden need in the society for appropriate Palliative Care (PC).

Since 2006, individual attempts are being taken to introduce $\mathrm{PC}$ in the country. The major breakthrough came when Bangabandhu Sheikh Mujib Medical University (BSMMU), the only Medical University of the country introduced and incorporated PC in its services on $6^{\text {th }}$ October, 2007.

Like any other country, this initiative has to be associated with a corresponding change in the education and attitudes of the health care professionals $^{3,4}$.There is an enormous need for palliative care education and training of health professional in the developing world where palliative care is most needed ${ }^{5}$. Bangladesh is no exception to this. Unfortunately, symptom management of terminally ill patients, clinical use of opioids, communication skill of breaking bad news and end of life issues and ethics discussion remains astonishingly poor amongst health care professionals during both undergraduate and post graduate teaching and training. There are 15 medical colleges in public sector and 34 in private sectors in the country which produce about 2600 doctors a year. According to HRD 2007 data sheet, total number of estimated doctors available in the country is approx $39000{ }^{6}$. None of these to our best knowledge have palliative care in their undergraduate training. The Medical University has recently begun a 3 day introductory course which is the first of its kind in the country. Before the introduction, we decided to conduct a survey to determine the level of perception and understanding in palliative care both amongst future specialists working as trainee as well as the specialist doctors working as trainers in this university.

\section{Materials and methods:}

The palliative care service team of the university developed a questionnaire (Appendix-A) with their own exposure and experience in the field of palliative care.

The intent of the survey was to estimate the physicians perceived level of proficiency based on their own assessment of the quality of their education in palliative care. This survey was also a part of the awareness developing program amongst the professionals. One Hundred and Eighty Nine post graduate trainees (Group-1) were requested to fill in the questionnaire when they attended a lecture on Palliative Care as part of their orientation program during the beginning of their two year residency in the university. After explaining the aim of the survey 15 minutes were allocated to complete the form. Those who were not willing to participate were allowed to do so. Permission was obtained from the coordinator of the orientation program who was the Dean of the Faculty of Surgery.

Eighty one post graduate qualified doctors (Group 2 ) were requested to fill-in the survey while they came to attend the three day introductory course on palliative care or showed their interest to develop the service in the university before the course. They were also approached by the authors on individual basis.

Both were a heterogeneous cohort from different clinical subspecialty like internal medicine, anesthesiology, gynaecology, surgery etc but all were working in the BSMMU at the time of the survey.

Participants were asked in first five questions to rate their self perception of education in Palliative Care at MBBS level, ability of pain management in palliative care setting, to prescribe oral morphine in cancer pain, ability of breaking bad news to patients/ families and to face end-of-life issues of the patients. The range of possible positive responses like 'Excellent'; 'Very good' \& 'Adequate' and negative responses like 'Poor' and 'Nil' were provided to the participant at the end of each question of the first five. The last five questions, sixth to tenth, were more subjective in nature, of an opinion inviting type covering basic theoretical issues commonly discussed in palliative care teaching and training modules.

The focus was the participants own perception of their level of education as well as an attempt to validate that perception. Therefore, no other data regarding the participants, e.g. gender, age etc were collected. The intention was to assess the responses as a percentage of positive responses as well as negative response.

\section{Results:}

One Hundred and Twenty Seven postgraduate trainees out of 189 filled out the survey questionnaire (response rate 67\%). Out of nearly 200 Postgraduate 
clinical teachers of the BSMMU, 81 completed the survey which is about $41 \%$ of the trainers of the university. In total, 181 participants completed the survey although not every question was answered by each respondent. $61 \%$ respondents answered completely.

With regard to education in Palliative Care (Q1) positive response was much higher in Postgraduate Trainees (72\%) compared to the trainers (3.7\%). Similar was the level of confidence about the ability in pain management (Q2) which was higher in Gr. 1 (63\%) than Gr. -2 (40.7\%). Not many trainees and trainers ( $33.8 \%$ vs. $25.9 \%$ ) felt adequately trained to prescribe oral morphine in cancer pain (Q.3) Ninety percent trainees felt confident to communicate in breaking bad news to Patients/ families whereas $66.6 \%$ Postgraduate trainers felt the same.(Q.4). Postgraduate trainees felt more confident to face endof -life issues of patient (Q.5) (88.8\% vs. 59.2\%) than their trainers. (Table-I \& Table II).
Regarding the second part of the questionnaires, most of the physicians of both the group were of the opinion that the patient and the family had the right to know the diagnosis of the disease (90.5\% \& 85\%). Seventy four percent of the postgraduate physicians know that Palliative medicine is a subspecialty in some countries (Q.7) and this fact is known to $52.7 \%$ of the trainees. Most of the physicians of both the groups felt that skill in communicating with patients/ families can be improved with training (Q.8). Regarding Euthanasia, many respondents (32\%) did not answer this question. However, fewer trainers than trainees ( $41 \%$ vs. $48 \%)$.thought that there could be any logic in favor of euthanasia. Approximately $40 \%$ of both the groups are against the idea of euthanasia. Most of both the groups prefer to die in their own home. (Table III).

\section{Palliative care concepts among postgraduate trainees and Postgraduate trainers.}

Table-I

Postgraduate Trainees $(n=127)$

\begin{tabular}{lccccc}
\hline Questions & Excellent (\%) & Very good (\%) & Adequate (\%) & Poor (\%) & Nil (\%) \\
\hline Q.1 & $7(5.5 \%)$ & $12(9.4 \%)$ & $53(41.7 \%)$ & $46(36.2 \%)$ & $7(5.5 \%)$ \\
Q.2 & $5(3.4 \%)$ & $20(19.6 \%)$ & $55(43.7 \%)$ & $39(10.7 \%)$ & $7(5.5 \%)$ \\
Q.3 & $2(1.5 \%)$ & $7(5.5 \%)$ & $34(26.7 \%)$ & $40(31.4 \%)$ & $46(36.2 \%)$ \\
Q.4 & $9(7.8 \%)$ & $41(32.2 \%)$ & $64(50.3 \%)$ & $12(9.4 \%)$ & $0(0 \%)$ \\
Q.5 & $8(6.2 \%)$ & $24(18.8 \%)$ & $72(56.6 \%)$ & $20(15.7 \%)$ & $0(0 \%)$ \\
\hline
\end{tabular}

Data are expressed as absolute number. Within parenthesis are percentage over total of the group.

Table-II

Postgraduate trainers $(n=81)$

\begin{tabular}{lccccc}
\hline Questions & Excellent (\%) & Very good (\%) & Adequate (\%) & Poor (\%) & Nil (\%) \\
\hline Q.1 & 0 & 0 & $3(3.7 \%)$ & $36(44.4 \%)$ & $30(37 \%)$ \\
Q.2 & 0 & $12(14.8 \%)$ & $21(25.9 \%)$ & $36(44.4 \%)$ & $9(11.1 \%)$ \\
Q.3 & $3(3.7 \%)$ & $9(11.1 \%)$ & $9(11.1 \%)$ & $27(33.3 \%)$ & $24(29.6 \%)$ \\
Q.4 & $3(3.7 \%)$ & $15(18.5 \%)$ & $36(44.4 \%)$ & $18(22.2 \%)$ & $3(3.7 \%)$ \\
Q.5 & 0 & $24(29.6 \%)$ & $24(29.6 \%)$ & $21(25.9 \%)$ & 0 \\
\hline
\end{tabular}

Data are expressed as absolute number. Within parenthesis are percentages over total of the group. 
Table-III

Comparison between the Postgraduate trainees (Group 1) and Postgraduate Trainers (Group-2).

\begin{tabular}{|c|c|c|c|c|c|}
\hline & \multirow[t]{2}{*}{ Questions } & \multicolumn{2}{|c|}{ (Group-II, n=127) } & \multicolumn{2}{|c|}{ (group-II,n = 81) } \\
\hline & & Yes (\%) & $\mathrm{No}(\%)$ & Yes(\%) & No $(\%)$ \\
\hline 1. & $\begin{array}{l}\text { Your education in Palliative care during } \\
\text { your MBBS level }\end{array}$ & $72(56.6 \%)$ & $53(41.7 \%)$ & $3(3.7 \%)$ & $66(81.4 \%)$ \\
\hline 2. & $\begin{array}{l}\text { Your ability in pain management in palliative } \\
\text { care setting }\end{array}$ & $80(62.9 \%)$ & $46(36.2 \%)$ & $33(40.7 \%)$ & $45(55.5 \%)$ \\
\hline 3. & $\begin{array}{l}\text { Your ability to prescribe oral Morphine in } \\
\text { cancer pain }\end{array}$ & $43(33.8 \%)$ & $86(67.7 \%)$ & $21(25.9 \%)$ & $51(62.9 \%)$ \\
\hline 4. & $\begin{array}{l}\text { Your ability to communicate in breaking very } \\
\text { bad news to patients/families }\end{array}$ & $114(89.7 \%)$ & $12(9.4 \%)$ & $54(66.6 \%)$ & $21(25.9 \%)$ \\
\hline 5. & $\begin{array}{l}\text { Your ability to face end of life issues of your } \\
\text { patients }\end{array}$ & $104(88.8 \%)$ & $20(15.7 \%)$ & $48(59.2 \%)$ & $21(25.9 \%)$ \\
\hline 6. & $\begin{array}{l}\text { If a patient gets an incurable disease, do } \\
\text { you think that He/She should know the } \\
\text { diagnosis \& prognosis. }\end{array}$ & $115(90.5 \%)$ & $7(5.5 \%)$ & $69(85.1 \%)$ & $3(3.7 \%)$ \\
\hline 7. & $\begin{array}{l}\text { Do you know that palliative medicine is a } \\
\text { sub specialty in some countries }\end{array}$ & $67(52.7 \%)$ & $30(23.6 \%)$ & $60(74.0 \%)$ & $9(11.1 \%)$ \\
\hline 8. & $\begin{array}{l}\text { Do you think that training can improve doctor's } \\
\text { skill in communicating with patient/family }\end{array}$ & $116(91.3 \%)$ & $11(8.6 \%)$ & $66(81.4 \%)$ & $9(11.1 \%)$ \\
\hline 9. & $\begin{array}{l}\text { Do you think that there is any logic in favor } \\
\text { of Euthanasia }\end{array}$ & $61(48.0 \%)$ & $30(23.6 \%)$ & $33(40.7 \%)$ & $30(37.0 \%)$ \\
\hline & $\begin{array}{l}\text { If you are given a choice, where would you } \\
\text { like to die (at home?) }\end{array}$ & $86(67.7 \%)$ & $30(23.6 \%)$ & $18(22.2 \%)$ & $48(59.2 \%)$ \\
\hline
\end{tabular}

Table-IV

Comparison between the two groups as a percentage of the total response. Postgraduate trainees/ Postgraduate trainers

Questions

\begin{tabular}{|c|c|c|c|c|c|c|}
\hline Q.6 & $\begin{array}{l}\text { Yes } 71(55.9 \%) \\
/ 45(55.5 \%)\end{array}$ & $\begin{array}{l}\text { No } 7(5.5 \%) / \\
3(3.7 \%)\end{array}$ & $\begin{array}{l}\text { Always } \\
1(.78 \%) / 0(0 \%)\end{array}$ & & $\begin{array}{l}\text { If Patient } \\
\text { wants to } \\
\text { know }(\%) \\
18(14.1 \%) / \\
12(14.8 \%)\end{array}$ & $\begin{array}{l}\text { If family } \\
\text { wants to } \\
\text { know (\%) } \\
25(19.6 \%) / \\
12(14.8 \%)\end{array}$ \\
\hline Q.7 & $\begin{array}{l}\text { Yes } 67(52.7 \%) \\
/ 60(74 \%)\end{array}$ & $\begin{array}{l}\text { No } 30(23.6 \%) \\
\text { / } 9(11.1 \%)\end{array}$ & & & & \\
\hline Q.8 & $\begin{array}{l}\text { Yes } 108(85 \%) \\
/ 66(81.4 \%)\end{array}$ & $\begin{array}{l}\text { No } 11(8.6 \%) \\
/ 0(0 \%)\end{array}$ & $\begin{array}{l}\text { Sometimes } \\
8(6.4 \%) \\
/ 9(11.1 \%)\end{array}$ & & & \\
\hline Q.9 & $\begin{array}{l}\text { Yes } 31(24.4 \%) \\
/ 18(22.2 \%)\end{array}$ & $\begin{array}{l}\text { No } 17(13.3 \%) \\
/ 15(18.5 \%)\end{array}$ & $\begin{array}{c}\text { Sometimes } \\
30(23.6 \%) / \\
15(18.5 \%)\end{array}$ & $\begin{array}{l}\text { Don't know } \\
35(27.5 \%) / \\
15(18.5 \%)\end{array}$ & & \\
\hline Q.10 & $\begin{array}{l}\text { Hospital } \\
15(11.8 \%) / \\
12(15.8 \%)\end{array}$ & $\begin{array}{l}\text { Home } \\
86(67.7 \%) / \\
48(49.2 \%)\end{array}$ & $\begin{array}{l}\text { ICU } 10 \\
(7.8 \%) / \\
3(3.7 \%)\end{array}$ & $\begin{array}{l}\text { best hospital } \\
5(3.9 \%) / \\
3(3.7 \%)\end{array}$ & road & \\
\hline
\end{tabular}




\section{APPENDIX: I}

\section{Questionnaires:}

1. Your education in Palliative care during your MBBS level
a) Excellent b) Very good, c) Adequate d) Poor e) Nil

2. Your ability in pain management in palliative care setting
a) Excellent b) Very good, c) Adequate d) Poor e) Nil

3. Your ability to prescribe oral Morphine in cancer pain

a) Excellent b) Very good, c) Adequate d) Poor e) Nil

4. Your ability to communicate in breaking very bad news to patients/families

a) Excellent b) Very good, c) Adequate d) Poor e) Nil

5. Your ability to face end of life issues of your patients

a) Excellent b) Very good, c) Adequate d) Poor e) Nil

6. If a patient gets an incurable disease, do you think that He/She should know the diagnosis \& prognosis? a) Yes b) No c) Always d) if the pt wants to know e)if family wants to know

7. Do you know that palliative medicine is a sub specialty in some countries

a) Yes b) No

8. Do you think that training can improve doctor's skill in communicating with patient/family

a) Yes b) No c)Sometimes

9. Do you think that there is any logic in favor of Euthanasia

a) Yes b) No c) Sometimes d) Don't know

10. If you are given a choice, where would you like to die (at home?)

a) Hospital b) Home c) ICU d) Best hospital abroad

\section{Discussion:}

This is, to our knowledge, the first such study conducted on palliative care concept among the physicians in Bangladesh. We compared the results of the post graduate trainee versus their trainers (Table IV) .Our assumption was that the physicians, in general, in Bangladesh had very limited knowledge of palliative care. A staggering low level of only 4 per cent post graduate trainers claiming their undergraduate exposure in palliative care education as adequate supported our assumption. The survey revealed that approximately half of this group (55\% and 69\%) expressed their lack of confidence in cancer pain management as well as in prescribing oral morphine. The finding of the survey was surprisingly different in case of group 1 , which is the trainee group. A very positive response by this group for the first five questions both in absolute and relative number took us by surprise. This group claimed an overall higher ability than their trainers in all the basic components of palliative care issues mentioned in the questionnaire. The dilemma is that a number of valid arguments could be proposed both in favor and against this observation. It could be argued that the trainees are relatively fresh medical graduates, more recent knowledge based and motivated by their self learning attitude which places them as post graduate trainees. Mention of palliative care and the concept are more pronounced in the latest text books that these trainee have to study for their post graduation $^{8}$. On the contrary, one must also consider that these responses do not indicate the actual level of education in palliative care. These are the perceived level of proficiency and ability based on one's own perception and self assessment. This suspicion is also supported by the observation that rate of positive response goes down when the issues of specific skill like managing cancer pain and oral morphine prescription arise. It is also known that in most of the medical schools of the world students significantly lack personal or academic knowledge about pain and negative attitudes toward opioids ${ }^{9}$. The main reason is possibly the global trend towards 
a disease and cure oriented approach and this is reflected in the medical and nursing education. But, then why such unanticipated high positive response rate, particularly by the trainees! The findings need to be judged also in the context of arrogance-ignorance paradox ${ }^{10}$. Our findings of the survey are interestingly similar to a few other surveys done in the some other developing as well as developed countries ${ }^{11,12,13}$. A similar percentage to our finding of interns ( $82 \%)$ and students (86\%) reported to be familiar with the concept of Palliative Care in a recent survey in India,11. This study investigated Palliative Care concepts among medical interns and students in India who had no mandatory Palliative Care curriculum. Another similar study show that students $(97.9 \%)$ and interns (81.2\%) reported familiarity with the concept of Palliative Care in a study in Vienna ${ }^{12}$. Results of a recent survey of resident physicians in post-graduate training programs in Chile shows that approximately $50 \%$ respondents perceived that their level of palliative care education was adequate. Interestingly, only $11 \%$ of the residents received formal palliative care education and $25 \%$ considered themselves to have very good proficiency in the use of opioids for pain control $^{8}$.

\section{Conclusion:}

The main draw back of this study are quite a number including the heterogeneity of the participants, too generalized questions, not piloting the questionnaire before the actual survey .The findings of this study tend to reflect the experience and perception of one institution where physicians with better academic background aggregate together. However, this was an attempt to determine the level of perception of the doctors in Bangladesh in their own understanding. It was also a part of the awareness creation program in the university. The authors are confident in stating that the actual level of understanding may not be the same as the perceived level showed by the study. This survey can be replicated in other institutions also. This study can be followed by more objective study to evaluate the actual knowledge base of the physicians regarding palliative care.

The ultimate goal of medical education, as well as clinical interventions, is improved patient care. The dying members of the society should not be deprived of a 'good death' due to the lack of proper education and skill attainment.

\section{References:}

1. Jan Stjernsward, David Clark. Palliative Medicine- a global perspective in, Oxford textbook of palliative medicine $3^{\text {rd }}$ edition.Ed: Doyle D., Hanks G., Cherny N., Calman K. Oxford University press NY 2005.

2. Aranda S. Global perspectives on palliative care: Cancer Nursing1999; 22(1): 33-39

3. Herman TA. Terminally ill patients: assessment of physician attitudes within a teaching institution. N Y State J Med 1980; 80: 200-207.

4. Macleod RD: On reflection: doctors learning to care for people who are dying. Soc Sci Med 2001; 52: 1719-1727.

5. Pain and palliative care in the developing world and marginalized populations-A global challenge. Ed: Raja Gopal M.R., Mazza D., Lipman A.G.The Haworth medical press; 2003.

6. The State of Health in Bangladesh 2007. Health Workforce in Bangladesh, Bangladesh Health Watch, BRAC university.

7. Bhardawaj P, Vidyasagar MS, Kakria A, AlamU A: Survey of Palliative Care Concepts among Medical Interns in India. Journal of Palliative Medicine , 2007;10 (3): 654-657

8. Nervi F, Guerrero M, Reyes MM, Symptom Control and Palliative Care in Chile Journal of Pain and Palliative Care Pharmacotherapy 2003; 17 (3/4): 13-22.

9. Fidelis M, Manalo C: Knowledge Toward Cancer Pain and the Use of Opioids Analgesics Among Medical Students in their Integrated Clinical Clerkship. Palliative Care Research and Treatment. Accessible at http://la.press.com

10. Von Gunten CF: Arrogance ignorance paradox. J Palliative Medicine 2005; 8: 898-899.

11. Bhardawaj P, Vidyasagar MS, Kakria A, AlamU A: Survey of Palliative Care Concepts among Medical Students in India. Journal of Palliative Medicine , 2007; 10 (3): 651-653

12. Pohl G., Marosi C., Dieckmann K., Goldner G., Elandt K., Hassler M.: Survey of Palliative Care Concepts Among Medical Students and Interns in Austria: A Comparison of the Old and New Curriculum of the Medical University of Vienna. Palliative care: Research and Treatment 2008; 2: 1-7

13. Schwartz C, Goulet J L, Gorski V, Selwin P A.: Medical Residents' Perceptions of End-ofLife Care Training in a Large Urban Teaching Hospital. Journal of Palliative Medicine 2003; 6(1): 37-43. 